\title{
UNIVERSIDADE NA ESCOLA: AÇÕES EM FEIRAS E EXPOSIÇÕES ESCOLARES E AS ATIVIDADES DO CAMPUS DE ANANINDEUA DA UFPA (2018-2019)
}

\author{
SCHOOL AT UNIVERSITY: ACTIONS AT SCHOOL FAIRS \\ AND EXHIBITIONS AND THE ACTIVITIES OF THE \\ ANANINDEUA CAMPUS OF UFPA (2018-2019)
}

\author{
Francivaldo Alves Nunes* \\ ORCID: https://orcid.org/0000-0002-2750-0625 \\ Jhonny dos Santos Ramos** \\ ORCID: https://orcid.org/0000-0002-1016-6472
}

\section{RESUMO:}

Este texto tem o objetivo de relatar as experiências vivenciadas através do projeto de extensão "Universidade na escola". Trata-se de uma estratégia extensionista que envolveu alunos e professores de graduação e que tinha o propósito de apresentar as ações desenvolvidas no Campus de Ananindeua da UFPA em feiras, exposições e eventos escolares dos municípios da região Metropolitana de Belém, promovidos pelas instituições de ensino, ciência e tecnologia, nos anos de 2018 e 2019. Através de equipamentos de divulgação, como folders, cartazes, encartes e banners, assim como protótipos e experimentos, busca-se apresentar nestes eventos escolares os projetos, programas, cursos, ações de laboratório como estratégias de compartilhar as atividades construídas no ambiente acadêmico à sociedade, assim como divulgar o nome da instituição nos espaços escolares.

Palavras-chave: Feiras e exposições; Ciência e tecnologia; Universidade; Sociedade.

\begin{abstract}
:
This text aims to report the experiences lived through the extension project "University at school". It is an extension strategy that involves undergraduate students and teachers with the purpose to present the actions developed at UFPA's Ananindeua Campus targeting fairs, exhibitions and school events in the cities of the Metropolitan Region of Belém promoted by education, science and technology institutions. Through dissemination equipment, such as leaflets, posters, inserts and banners, as well as prototypes and experiments, we seek to present in these school events the projects, programs, courses, and laboratory actions as strategies to share the activities built in the academic environment with the community, as well as to advertise the name of the institution in school spaces.
\end{abstract}

Keywords: Fairs and exhibitions; Science and technology; University; Society. 


\section{Conhecendo o projeto}

O Campus Universitário de Ananindeua (CANAN), da Universidade Federal do Pará (UFPA), sediado no município de Ananindeua, possuía nos anos de atividades do projeto (2018-2019) sete cursos de graduação (História, Geografia, Química, Física, Ciência e Tecnologia, Geoprocessamento, Engenharia de Materiais), um Mestrado em Ensino de História, quatro laboratórios (física, química, informática e geoprocessamento) e uma biblioteca. Com mais de 1.000 alunos, 40 técnicos e 40 professores, tem atuado nas áreas de ensino, pesquisa e extensão, principalmente através de projetos desenvolvidos por professores e técnicos. No caso dos projetos de extensão, estes são pensados a partir da necessidade que o Campus tem, a cada momento, de assumir um compromisso cada vez mais sólido com a comunidade onde está inserido, no caso, a Região Metropolitana de Belém (RMB), Estado do Pará.

O CANAN foi criado através da Resolução n ${ }^{\circ} 717$, de 12 de agosto de 2013, e apresenta como proposta investir na formação profissional e tecnológica, em atenção às transformações sociais que se apresentam no Estado do Pará e, em particular, no município de Ananindeua e RMB. No caso, trata-se de área que compreende ainda os municípios de Marituba, Benevides, Benfica, Santa Isabel e Santa Barbara, podendo atender ainda a outros municípios mais próximos, como Santo Antonio do Tauá, Vigia, Colares, São Caetano de Odivelas, Curuçá, São João da Ponta, Bujarú, Terra Alta e Marapanim.

Preocupado com a formação profissional integral, com a produção de conhecimento para o desenvolvimento humano, socioeconômico e cultural, assim como para atender às necessidades do mercado de trabalho regional, o CANAN lançou o projeto de extensão "Universidade na escola: ações em feira e exposição escolares como estratégias de apresentar as atividades do Campus de Ananindeua da UFPA (2018-2019)". O projeto que tive a oportunidade de coordenar tinha a preocupação de mostrar aos alunos, pais, professores e diretores das escolas públicas e particulares da educação básica, estudantes de cursinho pré-vestibulares e para a comunidade regional, todo potencial de ensino, pesquisa e extensão desenvolvido pelo CANAN.

Pensando em potencializar esta aproximação entre a universidade e comunidade, lançamos este projeto de extensão como equipamento que permitia que o CANAN, através de seus alunos e professores, se apresentasse em feiras e exposições organizadas ou realizadas pelas escolas. A perspectiva era que, aos participar desses eventos, os discentes dos cursos de graduação, ao mesmo tempo em que apresentam de maneira concentrada as ações desenvolvidas pelo Campus, também exercitam conhecimento produzido no ambiente acadêmico. Para viabilizar este propósito de socializar as atividades acadêmicas, se construía uma estrutura de trabalho que possibilitou demonstrar o potencial de todos os cursos e espaços de formação, como as atividades desenvolvidas nos laboratórios e biblioteca.

Não há dúvidas de que o propósito das feiras e exposições é de incentivar a criatividade e a reflexão dos estudantes através da criação, desenvolvimento e apresentação 
de projetos científicos e tecnológicos em diversas áreas do conhecimento (ROSA, 1995, p. 27). Além disso, assume um importante papel social, incentivando a própria cultura à investigação, o desenvolvimento de competências como liderança e trabalho em equipe, assim como a inovação e o empreendedorismo na região.

Do ponto de vista institucional, as feiras e exposições permitem aproximar as instituições de ensino, sejam elas públicas ou privadas, com a sociedade e outras instituições, criando um ambiente de troca de experiência e socialização de conhecimentos no que atua cada entidades envolvida (KREINZ; PAVAN; MARCONDES FILHO, 2007). É também neste aspecto que este projeto se justifica, pois assegura o conhecimento do que produz a universidade, assim como permite conhecer ainda mais essas unidades escolares, criando possibilidades de trabalho em regime de cooperação.

Toda esta experiência permite ao estudante, da universidade e da escola, entrar em contato com diferentes culturas, criando diferentes canais de comunicação, seja no meio científico ou empresarial, o que colaborará para o desenvolvimento e reconhecimento de todos os envolvidos, direta e indiretamente, nestes espaços de feira e exposição (ABRACON, 2004, p. 63).

Do ponto de vista da região envolvida no projeto, este se justificava pela necessidade da pesquisa e que trabalhos acadêmicos possam ser difundidos entre a população, principalmente entre os estudantes da educação básica, servindo inclusive de feedback para que soluções e novas alternativas possam ser desenvolvidas e aplicadas. É necessário que as preocupações sociais atuais, incluindo o conhecimento científico, tenham relação com o cotidiano escolar, fazendo da escola um espaço social e cultural dinâmico e conectado às transformações no ambiente da ciência e da tecnologia. $\mathrm{O}$ fato é que, para a educação de qualquer cidadão no mundo contemporâneo, é fundamental que ele tanto possua noção no que concerne à ciência e tecnologia, mensurando seus principais resultados, métodos e usos, quanto no que se refere aos riscos e limitações, e, também, os interesses e determinações (econômicas, políticas, culturais e sociais) que presidem seus processos e aplicações. Ao que se observa, o desenvolvimento do projeto permitiu, por um lado, que os acadêmicos conhecessem as demandas sociais, uma vez que atuaram diretamente com a comunidade, e por outro, que esta sociedade, conhecendo o que produz a universidade, passe a valorizá-la ainda mais.

Do ponto de vista dos objetivos alcançados pelo projeto, destaca-se a oportunidade aos estudantes de ensino médio, cursinhos pré-vestibulares, professores e diretores de colégios públicos e particulares, pais e comunidade da região, um contato direto com os cursos superiores e as atividades acadêmicas desenvolvidas no ambiente universitário.

Além disso, podemos associar a apresentação do CANAN como uma alternativa potencial de formação profissional, assim como mostrar aos visitantes as tendências relativas às novas competências e habilidades requeridas aos profissionais de formação superior e as oportunidades formativas oferecidas pela universidade. São alguns outros 
objetivos contribuir para que a escolha dos candidatos sobre o vestibular seja mais consciente e segura, fornecendo informações sobre a universidade e os diversos campos profissionais; mostrar a estrutura física e humana da instituição e principalmente seu potencial no plano do ensino, pesquisa e extensão; divulgar o trabalho desenvolvido pelo CANAN em suas diversas áreas, assim como motivar a procura pelos cursos do campus.

Ao considerarmos as metas do projeto, foi possível envolver diretamente 14 alunos de graduação nas atividades, como monitores, um professor e um técnico do CANAN na coordenação e supervisão, respectivamente, assim como mais de 6 mil pessoas, entre alunos, professores e diretores das escolas públicas e particulares do ensino médio e estudantes de cursinhos pré-vestibulares, bem como a comunidade regional nos eventos.

Como observado, o projeto se propõe à construção de atividades que permitiram a aproximação entre o ensino acadêmico e o atendimento comunitário através da exposição das atividades desenvolvidas pelo CANAN, em feiras e exposições escolares na RMB. Nesse caso, pautamos a proposta em uma concepção de que a metodologia se constitui na busca em mostrar o caminho do pensamento para a abordagem da prática a ser estudada (MINAYO, 1994). Tendo em vista este pressuposto, envolveu professores do ensino superior, alunos de graduação, discentes e docentes da educação básica.

As atividades foram ainda pautadas tendo por base o princípio da indissociabilidade entre ensino, pesquisa e extensão, e na tomada da diversidade como estratégia de compreensão e análise dos atendidos pelo projeto. Ainda, se pautou na aproximação e inter-relação dos conhecimentos associados às práticas docentes, que envolvem o saber acadêmico e a experiência de vida dos alunos da educação básica que participarão como visitantes destas exposições e feiras. Neste aspecto, partimos do princípio de que as abordagens teóricas descritas em linguagens científicas precisam ser interpretadas e redimensionadas nos seus diferentes aspectos, e que a produção do conhecimento não apenas precisa ser apresentada, mas compartilhada em todas as etapas de sua gestação.

Do ponto de vista da administração das atividades, estas foram desenvolvidas por monitores ou voluntário e supervisionadas pela coordenação do projeto, tendo como principal função supervisionar, propor e orientar as atividades. No caso dos monitores, são alunos regularmente matriculados em cursos de graduação do CANAN, tendo como principais atividades preparar e organizar os materiais e equipamentos a serem utilizados nas feiras e exposições, assim como assegurar a apresentação destes materiais nos eventos escolares, considerando sua área de formação.

Os materiais expostos e que expressavam as atividades desenvolvidas no CANAN foram disponibilizados através de banners, cartazes, folders, protótipos e miniaturas, nos eventos apresentados a seguir. 
Quadro 1 - Resumo das participações em eventos

\begin{tabular}{|c|c|c|c|}
\hline Evento/Ano & Local & Realização & Característica \\
\hline $\begin{array}{l}\text { Feira Vocacional da } \\
\text { SEMED/2019 }\end{array}$ & Ananindeua & SEMED* & $\begin{array}{l}\text { Exposição sobre formação e perfil profissional } \\
\text { aos alunos das escolas de Ananindeua. }\end{array}$ \\
\hline $\begin{array}{l}\text { Feira Experimento de } \\
\text { Baixo Custo/2019 }\end{array}$ & Ananindeua & CANAN & $\begin{array}{l}\text { Promovido pela Faculdade de Física, } \\
\text { apresentava os experimentos de baixo custo } \\
\text { desenvolvidos em laboratório. }\end{array}$ \\
\hline Sábado Astronômico/2019 & Barcarena & CANAN & $\begin{array}{l}\text { A exposição reuniu observações astronômicas, } \\
\text { oficinas com experimentos e campeonato de } \\
\text { lançamento de foguetes. }\end{array}$ \\
\hline $\begin{array}{l}\text { Amostra Engenharia de } \\
\text { Materiais e preocupações } \\
\text { socioambientais/2019 }\end{array}$ & Ananindeua & CANAN & $\begin{array}{l}\text { Organizado por docentes e discentes da } \\
\text { Faculdade de Engenharia de Materiais, expôs } \\
\text { estudos científicos com preocupações } \\
\text { ambientais. }\end{array}$ \\
\hline $\begin{array}{l}\text { Workshop de Tecnologia } \\
\text { para Ensino de Física/ } \\
2019\end{array}$ & Curuçá & CANAN & $\begin{array}{l}\text { Exposição de materiais didáticos associados ao } \\
\text { ensino de física. }\end{array}$ \\
\hline $\begin{array}{l}\text { Amostra de História do } \\
\text { Brasil Oitocentista/2019 }\end{array}$ & Ananindeua & CANAN & $\begin{array}{l}\text { Exposição de jogos, mapas interativos, teatro, } \\
\text { poesia e gibis como materiais didáticos. }\end{array}$ \\
\hline $\begin{array}{l}\text { I Feira Regional de } \\
\text { Matemática/2018 }\end{array}$ & Marituba & SEDUC $^{* *}$ & $\begin{array}{l}\text { Reuniu escolas e universidades do Estado do } \\
\text { Pará que desenvolvem pesquisas em } \\
\text { Matemática. }\end{array}$ \\
\hline $\begin{array}{l}\text { Feira de Profissões do } \\
\text { Sistema/2018 }\end{array}$ & Ananindeua & $\begin{array}{l}\text { Colégio } \\
\text { Sistema }\end{array}$ & $\begin{array}{l}\text { Exposição sobre formação e perfil profissional } \\
\text { aos alunos das escolas de Ananindeua. }\end{array}$ \\
\hline $\begin{array}{l}\text { Feira Vocacional do } \\
\text { Pará/2018 }\end{array}$ & Marituba & SEDUC & $\begin{array}{l}\text { Exposição sobre formação e perfil profissional } \\
\text { aos alunos de escolas da educação básica. }\end{array}$ \\
\hline $\begin{array}{l}\text { IX Feira Estadual de } \\
\text { Ciência, Tecnologia e } \\
\text { Inovação/2018 }\end{array}$ & Belém & SECTET $^{* * *}$ & $\begin{array}{l}\text { Exposição sobre formação, perfil profissional e } \\
\text { pesquisas científicas aos estudantes e sociedade } \\
\text { paraense. }\end{array}$ \\
\hline $\begin{array}{l}\text { Feira Vocacional } \\
\text { Supremo/2018 }\end{array}$ & Ananindeua & $\begin{array}{l}\text { Colégio } \\
\text { Supremo }\end{array}$ & $\begin{array}{l}\text { Exposição sobre formação e perfil profissional } \\
\text { aos alunos das escolas de Ananindeua. }\end{array}$ \\
\hline Feira Vocacional/2018 & Benevides & $\begin{array}{l}\text { Escola } \\
\text { Estadual } \\
\text { "Otávio } \\
\text { Meira" }\end{array}$ & $\begin{array}{l}\text { Exposição sobre formação e perfil profissional } \\
\text { aos alunos das escolas de Benevides. }\end{array}$ \\
\hline
\end{tabular}

* Secretaria Municipal de Educação de Ananindeua

**Secretaria de Estado de Educação do Pará

***Secretaria de Ciência, Tecnologia e Educação Profissional e Tecnológica do Estado do Pará.

Fonte: Os autores 


\section{Nas escolas a universidade: o projeto em ações}

No desenvolvimento das ações do projeto, inicialmente tivemos a preocupação de promover a capacitação dos agentes envolvidos, principalmente os monitores, com o aprofundamento histórico e epistemológico da concepção de feiras e eventos em ambientes escolares e suas potencialidades como exposição, mas também promoção do conhecimento. Para isso, disponibilizamos leituras de materiais que foram discutidos em grupos de trabalho e aprendizagem de forma dialógica.

As leituras pautaram-se na conceituação de eventos, participação, formação e exposição. No caso dos significados de feiras e eventos escolares, buscou-se trabalhar com a ideia de ação profissional mediante pesquisa, planejamento, organização, coordenação e controle, visando atingir seu público-alvo com medidas concretas e resultados projetados. Para isso, foram utilizados os textos de Matias (2004), Allen (2003) e Giacomo (1993).

Os eventos escolares em que o projeto foi executado apresentavam, em geral, como proposta, a realização de uma mostra científica e cultural aberta ao público, com o objetivo de incentivar a produção científica e as manifestações culturais nas escolas e instituições de ensino superior, a fim de possibilitar o acesso à ciência às pessoas de todas as idades e classes sociais, além de oferecer palestras, oficinas didático-pedagógicas e apresentações culturais. Sendo estas propostas as principais metas dos eventos, a finalidade era despertar nos estudantes o interesse pela ciência e levá-los ao exercício da metodologia científica no desenvolvimento de pesquisas. É neste ambiente de exposição que o projeto é executado e aponta suas ações voltadas para demonstrar os cursos de graduação e o perfil de atuação profissional dos estudantes formados na universidade, em especial no CANAN.

As programações dos eventos previam, em sua totalidade, o debate acerca de conhecimentos associados à universalidade, como os direitos dos estudantes ou da importância do ensino e da escola, ou de temas voltados para saneamento, combate à violência, importância da leitura, dos direitos humanos, além de temas relacionados ao desenvolvimento de processos científicos e tecnológicos envolvidos com sua utilização. A discussão envolvendo temas de relevância social e acadêmica era, em alguns casos, objeto de palestras dos professores e técnicos do CANAN. Esta ação específica, além de permitir o conhecimento acadêmico no ambiente da escola, possibilitava a interação entre a população e a comunidade acadêmico-científica, promovendo educação de qualidade e garantindo a estrutura necessária para uma formação democrática, cidadã, sustentável e humana.

As modalidades de trabalhos desenvolvidos pelos monitores do projeto permitiram a construção de produtos para exposição, como maquetes, posters, banners que expressassem as atividades e perfil profissional dos cursos. Trata-se de materiais que permitiram a prestação de serviço do que se faz na universidade, promoveram o entendimento e demonstraram o resultado do trabalho dos monitores. São produtos que, ao mesmo tempo que expõem conteúdos e informações, permitem a apropriação desse conhecimento por parte dos frequentadores dos eventos, assim como dos próprios monitores que participaram da elaboração do material. 
Outra faceta é a investigação, pois permite, com a pesquisa, a busca e solução de problemas, assim como o desenvolvimento de aprendizagem pelos monitores principalmente, uma vez que a confecção desses materiais de exposição obedece à sequência coerente do método científico (problema, hipóteses, dedução, testagem, conclusão).

As atividades do projeto levaram em consideração as feiras nas escolas e na universidade como experiências que se destacam por substituir a recepção passiva pela construção do conhecimento por parte do aluno, o qual apresenta um projeto científico desenvolvido ao longo de um período, em que foi elencado um problema e, através de hipóteses, buscou-se uma solução. Dentro dessa perspectiva, a universidade pode colaborar ao expor os cursos de graduação e as atividades desenvolvidas pelos seus estudantes como estratégia para despertar a curiosidade e o interesse, mostrando-se como agente motivador e desafiador, permitindo o desenvolvimento intelectual e científico.

Como afirma Mezzari (2011, p. 111), as feiras escolares constituem momentos que despertam a curiosidade e o interesse dos estudantes da educação básica, principalmente quando utilizam materiais diferentes. Nesse aspecto, a experiência do que é desenvolvido na universidade pode ser importante. A própria prática de promover ou participar do evento é motivadora. Embalado por esse desafio de experimentar, o estudante ainda desperta seu desenvolvimento intelectual, ao mesmo tempo em que se esforça para pensar e resolver problemas, na busca incessante por resultados.

E, finalmente, o saber cotidiano passa a ser alvo de confronto. $\mathrm{O}$ aluno começa a ter novos posicionamentos diante dos experimentos e de seus resultados, adquirindo um saber mais científico, e nesse ponto, a universidade no espaço da escola, nas feiras e eventos pode, em muito, colaborar.

A participação em eventos escolares proporciona benefícios que podem ser compreendidos no crescimento pessoal e a ampliação dos conhecimentos, pois os alunos se mobilizam para buscar e aprofundar temas a serem expostos, assim como desenvolvem produtos que melhor expliquem o perfil profissional do curso de graduação e que vem sendo produzidos na universidade. Outra questão que se observa é a ampliação da capacidade comunicativa, devido à troca de ideias, ao intercâmbio cultural e ao relacionamento com outras pessoas.

Considerando que a linguagem é um poderoso instrumento de organização do pensamento, elaboração e sistematização de conhecimentos, o que se nota na apresentação de um trabalho em um evento é o desenvolvimento, no aluno, da sua capacidade de comunicar e discutir temas da ciência. Ao comunicar suas ideias para o público, os discentes as reorganizam até torná-las claras, primeiro para si e depois para quem vai assistir à sua apresentação. Como o público que comparece ao evento pode ser bastante diversificado, em idade e nível de conhecimento, existe por parte dos expositores um esforço em tornar compreensível o trabalho apresentado. Esse esforço exercita a habilidade de argumentação e a capacidade de compreender a perspectiva do público que ouve a explicação dada sobre o trabalho. 
As mudanças de hábitos e atitudes com o desenvolvimento da autoconfiança e da iniciativa, bem como a aquisição de habilidades como abstração, atenção, reflexão, análise, síntese e avaliação, são elementos de apropriação por parte dos discentes envolvidos no projeto. Trabalhos apresentados nos eventos escolares exigiram grande mobilização cognitiva e afetiva por parte dos alunos que, orientados pelos professores, desenvolveram um trabalho em que exercitavam sua capacidade de investigação e de construção de conhecimentos. As leituras, pesquisas ou a realização de experiências, bem como a necessidade de sistematização e de preparação da apresentação exigiram dos monitores um esforço que requereu planejamento e, quando realizado em grupo, trabalho em equipe.

O desenvolvimento da criticidade, com o amadurecimento da capacidade de avaliar o próprio trabalho e o dos outros, foi outra questão observada. Durante a realização de uma exposição, alunos e professores têm oportunidade de observar, discutir e examinar trabalhos realizados por outros, o que, inevitavelmente, gera comparação com o próprio trabalho. Essa é uma comparação saudável porque permite vislumbrar aspectos em que os trabalhos podem ser melhorados e quais inovações podem ser incorporadas, o que conduz a novas linhas de investigação e de construção de conhecimento científico e/ou tecnológico.

Os discentes envolvidos apresentaram maior interesse e, consequentemente, maior motivação para o estudo de temas relacionados à graduação, assim como colaboraram de forma mais significativa com a identificação com o curso. Como as produções apresentadas dizem respeito a temas escolhidos pelos próprios alunos, há um envolvimento afetivo com o estudo, a pesquisa e a preparação para a apresentação do trabalho. Esse envolvimento deixa de ser motivado apenas por receber uma nota ou avaliação, incluindo a dimensão da possibilidade de mostrar uma produção singular.

O exercício da criatividade conduz à apresentação de inovações dentro da área de estudo das ciências. Os discentes envolvidos com o projeto procuraram descobrir formas originais de realizar seus trabalhos, para que sua apresentação fosse interessante e atraísse o público visitante. Além disso, quando existe o incentivo por parte do público que visita as feiras e exposições, através de comentários sobre o que observam, isso pode estimular novos olhares críticos e criativos dos monitores do projeto, de forma a aperfeiçoarem os seus produtos e torná-los mais interativos.

Maior politização dos participantes devido à ampliação da visão de mundo, à formação de lideranças e à tomada de decisões durante a realização dos trabalhos é também percebida. A participação nas feiras nas escolas e universidades é fonte geradora de protagonismo dos discentes, os quais acabam realizando denúncias sociais e ambientais ou orientando o público sobre como atuar frente a problemas que podem ser solucionados utilizando o conhecimento científico e tecnológico estudado por eles, com bem adverte Hartmann e Zimmermann (2009, p. 3), ao estudarem as feiras nas escolas de educação básica.

De acordo com Santos (2012, p. 157), por meio das feiras escolares, os estudantes podem ainda desenvolver o interesse pelos assuntos relacionados a diferentes áreas do 
conhecimento e habilidades para a busca de informações e aprendizagem contínua, necessárias para as novas formas de acesso ao conhecimento. De fato, entendemos que este processo visa a melhorar a cultura científica e tecnológica dos estudantes, de forma a capacitar discussões em um mundo cada vez mais dependente de ciência e tecnologia.

Dessa forma, a atuação no projeto, ao se ajustarem as demandas da escola, pode proporcionar maior interação social entre alunos, professores e visitantes, estimular o prazer pelo trabalho da pesquisa, melhorar a argumentação teórica e modificar o uso da linguagem, em que a linguagem científica passa a ser mais utilizada. Logo, "a apresentação de trabalhos em feiras contribui, portanto, para a formação estética, emocional, social e política do aluno e do professor e cria oportunidades para sua participação nos debates dos problemas atuais" (SANTOS, 2012, p. 157).

Ao preparar o material para apresentação nas feiras escolares, os discentes de graduação podem desenvolver o exercício das melhores formas de se educar pela pesquisa, principalmente se esta for inclusa durante a formação inicial e durante a aprendizagem dos alunos (GALIAZZI; MORAES, 2002). Nesse caso, a necessidade de pensar a formação e o aprendizado pela pesquisa é também algo observado no projeto. Educar pela pesquisa implica transformá-los em sujeitos da sua própria formação e aprendizagem, por meio da construção de competências de crítica e de argumentação, o que leva a um processo de aprender a aprender com autonomia e criatividade.

Com esses princípios, educar pela pesquisa propõe a superação do conhecimento copiado, em que o ato de pesquisar passa a ser um princípio metodológico diário da aula, em que ela gira em torno de um questionamento reconstrutivo do conhecimento, englobando e acrescentando outros conhecimentos dos alunos, fortalecendo o poder de argumentação, discussão e melhoria na linguagem científica. Nesse processo, todos os envolvidos passam a ser sujeitos das atividades, além disso, numa formação por meio da pesquisa, constituem-se em pesquisadores de sua teoria e práticas pedagógicas, originando-se uma interação cooperativa e participativa. Dessa forma, as relações pedagógicas são transformadas, de modo que os alunos objetos desaparecem e surgem os alunos participantes, os quais conseguem compreender que são sujeitos do seu processo de aprendizagem e percebem que estão aprendendo.

Dentre os benefícios de educar pela pesquisa, encontram-se a capacidade de elaboração própria, o professor como mediador do processo, o reconhecimento de lacunas teóricas e práticas que influenciam no avanço do conhecimento, a construção de novos conhecimentos, a competência argumentativa, a formação crítica e o desenvolvimento de uma comunicação científica. Considerando-se esses fatores como essenciais para educar pela pesquisa, é possível notar que se pode fazer uma ponte com as feiras de ciência, uma vez que são encaradas como uma forma de educar pela pesquisa, já que permitem que o aluno se torne sujeito ativo do seu processo de aprendizagem. Colabora, ainda, para a argumentação, o desenvolvimento da crítica e da línguagem científica, além de proporcionar a interação entre pares, tornando o professor mediador desse processo, o qual desempenha o papel de orientar os alunos sobre os problemas, hipóteses e soluções. 
Portanto, o ato de educar pela pesquisa pode desempenhar um papel importante no processo de ensino-aprendizagem, uma vez que é capaz de ajudar a superar a racionalidade técnica, em que cada participante parte de suas próprias teorias, reconstruindo-as e utilizandoas para solucionar problemas emergentes, desenvolvendo uma autonomia, argumentação crítica, a sua linguagem científica, capacidade oral e na constituição de habilidades, o que torna os alunos sujeitos ativos do processo de aprendizagem. Logo, deve ser encarada como uma metodologia de ensino importante para desenvolver sujeitos críticos e autônomos.

Algumas questões ficaram evidentes aos discentes de graduação que atuaram no projeto e na apresentação dos cursos do CANAN nas feiras escolares e universitárias. A primeira percepção é que os eventos foram bem organizados e deixaram espaços estratégicos para que a universidade pudesse apresentar seus materiais para exposição, o que não apenas gerou as melhores condições de demonstrar seus produtos, como ainda proporcionou uma aprendizagem dinâmica e significativa. Outra questão é a percepção de que esses ambientes de feiras e exposições constituíram elos de ligações entre o que está sendo apresentado com o que foi desenvolvido ao longo de um determinado momento com os monitores. Além disso, as feiras, por se constituírem como espaços de caráter interdisciplinar, possibilitaram a disseminação do conhecimento para a sociedade de uma forma criativa e participativa, isto é, popularização e divulgação das conquistas científicas, aproximação e interação entre os estudantes da graduação e da educação básica.

Uma discussão importante, quando das avaliações posteriores à participação nos eventos, era as percepções dos monitores do projeto. Alguns apontavam percepções positivas marcadas pela motivação e envolvimento que este tipo de atividade proporcionava, assim como a oportunidade de colocar em prática o conhecimento teórico, sem contar a liberdade de se escolher temas com os quais se sentem mais à vontade para trabalhar. Um outro referencial importante observado é, ao apresentar os cursos aos alunos da educação básica e visitantes das exposições, esses discentes do ensino superior se sentem ainda mais valorizados, nas suas áreas de atuação. Do ponto de vista negativo, se observa que, para alguns participantes do projeto, se torna mais um acúmulo de trabalho e que em muitos casos provoca a perda de aulas. Por se tratar de eventos que ocorrem seguindo um calendário da escola, e não da universidade, as exposições não seguem uma sistematização, o que facilitaria maior planejamento, como se observa no Quadro 2, a seguir.

Quadro 2 - Avaliação da participação em feiras e exposições.

\begin{tabular}{|l|l|}
\hline \multicolumn{1}{|c|}{ Percepções positivas } & \multicolumn{1}{c|}{ Percepções negativas } \\
\hline $\begin{array}{l}\text { - Motivação e envolvimento; } \\
\text { - Melhor aprendizagem e ensino; }\end{array}$ & - Uma atividade a mais; \\
- Oportunidades de colocar em prática o \\
$\begin{array}{l}\text { conhecimento teórico; } \\
\text { - Liberdade de produção. }\end{array}$ & $\begin{array}{l}\text { - Exposição de trabalhos realizados de forma } \\
\text { extemporânea. }\end{array}$ \\
\hline
\end{tabular}

Fonte: Dados elaborados a partir de observações e entrevistas. 
Nos materiais apresentados de divulgação dos cursos e atividades desenvolvidas na universidade, observa-se que são trabalhos construídos em conjunto, coletivamente. Pautam-se pela aplicabilidade do conhecimento no cotidiano, como forma de atrair, inclusive, os alunos da educação básica. Não deixam, no entanto, de desenvolver concepções teóricas nos estudos apresentados, embora se trate de uma atividade prática. Por fim, se registra um aumento considerável de interesse pelos cursos e valorização da formação superior. Percebe-se a interação como fundamental para o desenvolvimento do projetos e de suas ações. Além disso, a constatação da teoria e aplicabilidade do conhecimento nos remetem a defesa do instrumentalismo como uma das melhores formas de aprendizagem, ou seja, faz parte da aprendizagem a necessidade de comprovar o pensamento por meio da ação (WESTBROOK; TEIXEIRA, 2010).

$\mathrm{Na}$ busca de compreender as concepções que os discentes do projeto constroem sobre a participação nestes eventos escolares, foi possível observar alguns efeitos mais gerais, na aprendizagem e na atitude desses alunos, como se registra:

Quadro 3 - Diagnóstico sobre a participação em feiras e exposições.

\begin{tabular}{|l|l|}
\hline \multicolumn{1}{|c|}{ Efeitos } & \multicolumn{1}{c|}{ Diagnósticos } \\
\hline Gerais & $\begin{array}{l}\text { Desenvolver e divulgar novos conhecimentos; } \\
\text { Motivar os alunos; } \\
\text { Aproximar o conhecimento teórico da prática. }\end{array}$ \\
\hline Aprendizagem & $\begin{array}{l}\text { Aprendizagem efetiva; } \\
\text { Colaborar para o desenvolvimento cognitivo; } \\
\text { Desenvolvimento do conhecimento por meio da investigação; } \\
\text { Aprendizagem livre e espontânea. }\end{array}$ \\
\hline Atitudinais & $\begin{array}{l}\text { Aprendem a trabalhar em grupo e a realizar pesquisas científicas; } \\
\text { Estimulam a criatividade; } \\
\text { Ampliação do interesse do aluno pela área científica; } \\
\text { Fortalecimento do espírito crítico, criativo e argumentação. }\end{array}$ \\
\hline
\end{tabular}

Fonte: Dados elaborados a partir de observações e entrevistas.

Analisando os efeitos gerais, atitudinais e de aprendizagem, é possível relacionálos à construção de atividades do projeto, pautados em grupo (interação), motivação e o desenvolvimento cognitivo, ou seja, itens fundamentais para o desenvolvimento do pensamento verbal e cognitivo. Quando se fala em colaboração, aplicabilidade da teoria na prática, aprendizagem efetiva por investigação, encontram-se características primordiais na percepção instrumentalista do conhecimento, uma vez que agir cientificamente é agir experimentalmente, em que se permite refletir, pensar e questionar, além do que os alunos podem estar em colaboração mútua, o que enriquece ainda mais o processo de aprendizagem. 
Participar das feiras escolares se apresenta, portanto, como estratégia para divulgar as atividades do CANAN, como destacamos, mas também para promover a ciência, incentivo à área científica, aumento do interesse, criatividade, criticidade e espírito investigativo. O que extrapola a ideia de um espaço apenas de exposição, mas também de produção de conhecimento e aprendizagem, e ainda, percebe-se a universidade na escola. Como bem registraram os estudos de Mancuso (2000), Mezzari (2009) e Hartmann e Zimmermann (2009), trata-se de um ambiente que desperta interesse, estimula criatividade, criticidade e a pesquisa, assim como permite desenvolver habilidade, argumentação e diálogo entre pares, ampliar o conhecimento, proporcionar maior envolvimento e interesse. $\mathrm{O}$ que bem se observou nos alunos de graduação que atuaram no projeto de extensão relatado neste texto.

Figuras 1 e 2: Participação dos monitores do projeto em feiras e exposições.
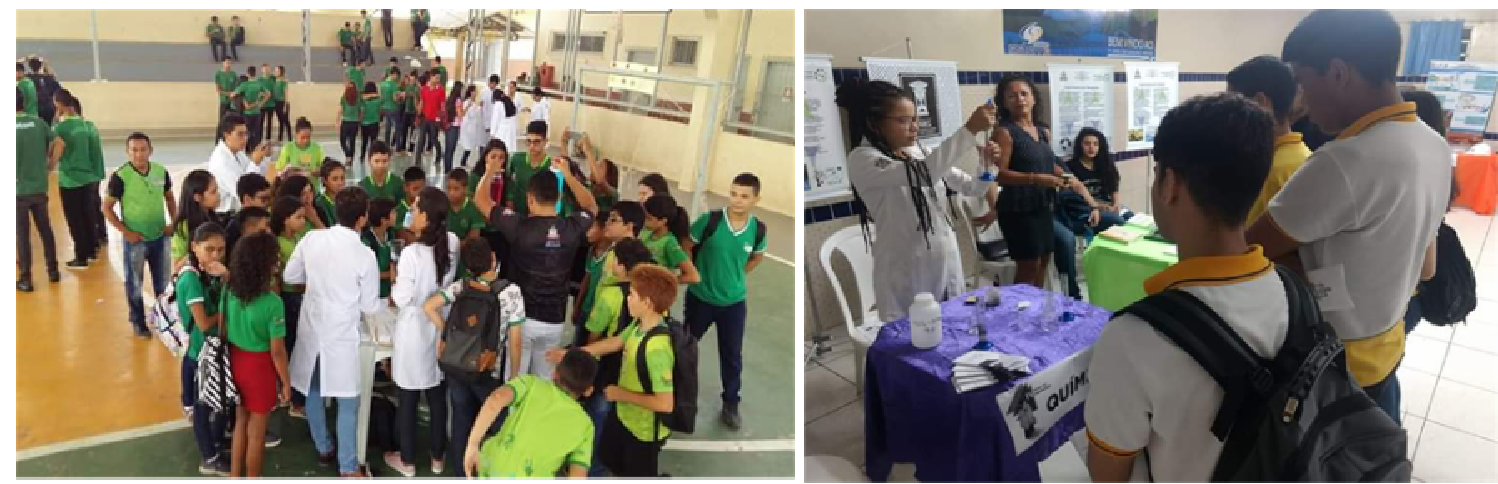

Fonte: Arquivo do Campus de Ananindeua-UFPA.

\section{Considerações finais}

Ao que foi registrado, a formação dos discentes dos cursos de graduação do CANAN que vivenciaram a experiência de participar em feiras e exposições, através do projeto "Universidade na escola", se mostrou importante e benéfica sobre os aspectos da apresentação do que era produzido no CANAN, assim como se tornou um espaço de exercício do que os monitores haviam aprendido nos cursos de graduação. Isto se confirma pois se mostraram motivados, proporcionando uma maior interação com os alunos da educação básica e comunidade.

Tratou-se de uma experiência importante para o desenvolvimento dos monitores quanto à argumentação, criatividade e criticidade, bem como de modo a possibilitar a autonomia para pesquisar e desenvolver produtores e materiais em assuntos de seus 
interesses. Além disso, ao construir estes materiais que deviam ser apresentados nas feiras e exposições, este momento foi pautado de motivação, instigação à pesquisa, bem como o desenvolvimento de habilidades.

A participação nos eventos permitiu uma maior interação entre pares, além de um melhor desenvolvimento cognitivo, aquisição de novos conhecimentos e, em determinadas situações, reconstruí-los. Vale ressaltar que, também, podem-se encontrar traços da produção de conhecimento voltados para aplicação na prática, considerando o que foi visto na teoria, e, ao trabalhar em grupo, existe uma colaboração para a construção e reconstrução de conceitos, tonando o processo de ensino e aprendizagem muito mais coletivo e participativo.

Ao participar dos eventos, observa-se uma ampliação do espaço para o desenvolvimento da curiosidade científica em sua dimensão histórica, social e cultural, considerando os questionamentos que surgem das experiências, expectativas e estudos teóricos dos alunos envolvidos no projeto. Além disso, constitui um espaço rico de possibilidades para as múltiplas expressões dos docentes. Como um lugar de acesso, exposição de conhecimento e de manifestação cultural, participar destes eventos desempenha um papel relevante, na medida em que introduz os alunos no universo das artes, da cultura e da investigação científica. A visibilidade destes trabalhos tem impacto direto na autoestima dos estudantes, promovendo maior identificação do aluno com seu curso de graduação.

Por fim, constatamos que o projeto constituiu uma grande oportunidade de aproximação da universidade nos ambientes escolares, construindo pontes de ligação entre esses dois espaços de formação. Nesse viés, ao mesmo tempo em que permitiu uma maior valorização do que a universidade vem desenvolvendo, a partir do conhecimento do que se produz no ensino superior, permitiu também que a escola fosse conhecida, o que deve impactar diretamente na própria formação dos alunos da graduação e, por conseguinte, dos alunos da educação básica.

Não há dúvidas de que estamos diante de uma experiência de extensão que não só permite estender os serviços extensionistas a ambientes sociais, como as escolas, como ainda se constituiu como atividades fundamentais para o crescimento profissional dos discentes envolvidos no projeto. A universidade na escola parece se tornar cada vez mais uma necessidade para qualificar a formação de discentes da graduação e da educação básica. 


\section{Referências}

ABRACON. Guia de feiras e congressos. 2004. Disponível em:

https://www.abracom.org.br/guiafeirasecongressos.pdf. Acesso em: 15 jul. 2017.

ALLEN, J. Organização e gestão de eventos. Rio de Janeiro: Campus, 2003.

BORBA, E. A importância do trabalho com Feiras e Clubes de Ciência: Repensando o Ensino de Ciências. Belo Horizonte: Secretaria de Estado da Educação de Minas Gerais, 1996. (Coleção Desenvolvimento Curricular, v.3: Caderno de Ação Cultural Educativa).

GALIAZZI, M. do C.; MORAES, R. Educação pela Pesquisa como modo, tempo e espaço de qualificação da formação de professores de Ciências. Ciência \& Educação, v. 8, n. 2, p. 237-252, 2002.

GIACOMO, Cristina. Tudo acaba em festa. São Paulo: Página Aberta, 1993.

HARTMANN, A. M.; ZIMMERMANN, E. Feira de Ciências: A interdisciplinaridade e contextualização em produções de estudantes de ensino médio. In: ENCONTRO

NACIONAL DE PESQUISA EM EDUCAÇÃO EM CIÊNCIAS, 7., Florianópolis, 2009.

KREINZ, G.; PAVAN, C.; MARCONDES FILHO, C. Feira de Reis: Cem Anos de

Divulgação Científica no Brasil - Homenagem a José Reis. São Paulo: NJR-ECA/USP, 2007.

LIMA, M. C. Feiras de ciências: a produção escolar veiculada e o desejo de conhecer o aluno. Recife: Espaço Ciência, 2007.

MANCUSO, R. Feiras de ciências: produção estudantil, avaliação, consequências. Contexto Educativo: Revista Digital de Educación y Nuevas Tecnologias, n. 6, p. 1-5, 2000.

MATIAS, M. Organização de eventos: procedimentos e técnicas. Barueri: Manole, 2004.

MEZZARI, S. Feiras multidisciplinares e o ensino de ciências. Revista Electrónica de Investigación y Docencia (REID), Número Monográfico, p. 107-119, 2011.

MINAYO, M. C. de S. (org.). Pesquisa social: teoria método e criatividade. Petrópolis: Vozes, 1994.

ORMASTRONI, M. J. S. Manual da Feira de Ciências. Brasília: CNPq, AED 30, 1990.

ROSA, P.R.S. Algumas Questões Relativas a Feiras de Ciências: para que servem e como devem ser organizadas. Caderno Brasileiro de Ensino de Física, v. 12, n.3, p. 223-228, dez. 1995. 
UNIVERSIDADE NA ESCOLA: AÇÕES EM FEIRAS E EXPOSIÇÕES ESCOLARES E AS ATIVIDADES DO CAMPUS DE ANANINDEUA DA UFPA (2018-2019)

Francivaldo Alves Nunes e Jhonny dos Santos Ramos

SANTOS, A. B. Feiras de Ciência: Um incentivo para desenvolvimento da cultura científica. Revista Ciência e Extensão, v.8, n.2, p. 155-185, 2012.

UFPA. Universidade Federal do Pará. Campus Universitário de Ananindeua. Resolução no 717, de 12 de agosto de 2013. Belém: UFPA, 2002.

WESTBROOK, Robert B. TEIXEIRA, Anísio. John Dewey. Recife: Fundação Joaquim Nabuco: Editora Massangana, 2010. 